\title{
Anti-fibrinolytic agents in bleeding disorders - A clinical perspective
}

\section{Saket Badle, Daniel Hart}

Tranexamic acid (TXA) is a synthetic antifibrinolytic drug used widely used to control bleeding complications in a wide variety of clinical situations. Soon after its development in the 1960 s it found use in treatment of women with menorrhagia, and in inherited bleeding disorders. Subsequently it was used in surgery and with proven efficacy to reduce transfusion requirements and bleeding complications. Recent meta-analysis have provided further evidence of efficacy and safety. Tranexamic acid is now on the World Health Organization's (WHO) list of essential drugs, and is the focus of ongoing worldwide trials. Similarly, there is increasing evidence base in both congenital and acquired bleeding disorders. We present a clinical narrative of the antifibrinolytic system and associated drugs to accompany the pharmacy review by Chaplin et al, with the aim of highlighting the evolution of TXA use in bleeding disorders over recent decades.

Keywords: antifibrinolytic agents, tranexamic acid, inherited bleeding disorders

Observations of a fibrinolytic effect were made by the Hippocratic school of medicine back in the 4th century BC, when it was observed that coagulated blood after death has the ability to undergo reliquefaction [1]. Investigators in the 18th and 19th centuries separately documented the spontaneous breakdown of blood clots, Jules A. F. Dastre coined the term fibrinolysis [1].

The haemostatic system in a healthy individual is in physiological balance between coagulation and fibrinolysis, the normal function of the latter leading to clot destruction and restoration of normal blood circulation. This balance may be upset in patients with inherited bleeding disorders who have normal fibrinolytic activity, such that physiological fibrinolytic activity may be sufficient to start bleeding after inadequate clot formation. In the acquired coagulopathy setting, e.g. trauma, hyperfibrinolysis is caused by activation of plasminogen activators and disseminated intravascular coagulation. Other than clearly demonstrable fibrinolysis in this setting, additional occult fibrinolysis appears to be detectable in those presenting with trauma and only subtly

Saket Badle, The Royal London Hospital Haemophilia Centre, Barts and The London School of Medicine and Dentistry, QMUL, UK. Email: Saket.Badle@ bartshealth.nhs.uk

Daniel P. Hart, The Royal London Hospital Haemophilia Centre, Barts and The London School of Medicine and Dentistry, QMUL, UK

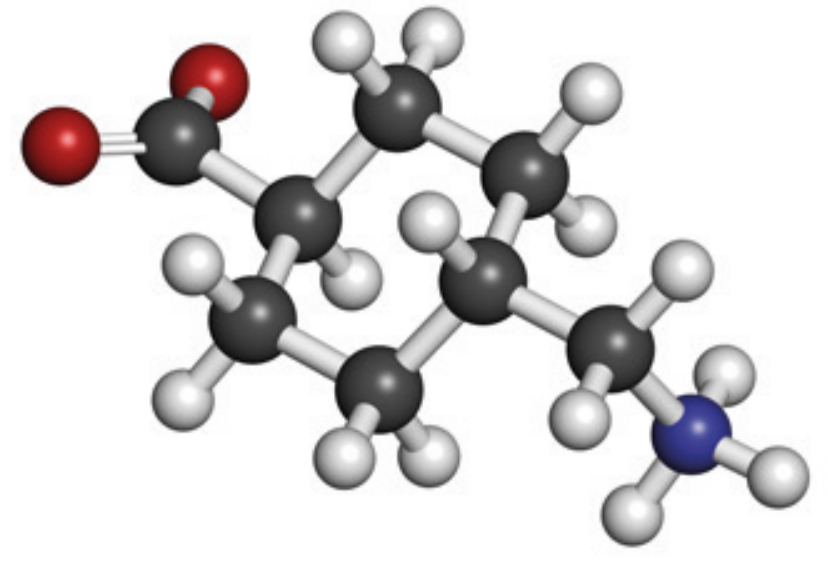

deranged routine clotting parameters [2].

(C) Shutterstock Inc

Antifibrinolytic drugs inhibit the breakdown of fibrin in blood clots. At present, three antifibrinolytic drugs are available: synthetic lysine analogues, epsilon-aminocaproic acid (EACA) and tranexamic acid, and the natural serine protease inhibitor, aprotinin. Aprotinin was isolated in 1930. Okamoto and colleagues discovered EACA in 1957 while searching for a substance with antifibrinolytic properties for use in prostatic and thoracic surgeries [3]. TXA was first reported as an inhibitor of fibrinolysis by Shosuke and Utako Okamoto in the Keio Journal of Medicine in 1962 [4]. TXA reversibly binds the lysine-binding site on the plasminogen molecule and inhibits the conversion of plasminogen to plasmin, thus impeding fibrinolysis. It is 6 to 10 times more potent than other antifibrinolytic agents.

Only since the 1980s have these drugs found more widespread use, the evidence base for such use in acquired coagulopathies only emerging in recent years. In 2009, following the lifesaving results of the CRASH 2 trauma trial, TXA was included in the WHO list of essential medicines. Ongoing large randomised controlled studies on its application in post-partum haemorrhage, head injury and acute gastrointestinal bleeding are expected to report imminently [5-7].

\section{Discussion}

Over the decades, TXA has been used to treat heavy menstrual bleeding, to reduce blood loss in elective surgery, and in orthopaedic, cardiac and liver surgery, where it has been shown to reduce transfusion requirements. It has also found use in hereditary angioedema and skin conditions 
such as melasma. The CRASH-2 trial results show reduction in bleeding-related all-cause mortality when TXA is used in trauma compared to placebo [8]. There have been anecdotal concerns about thromboembolic complications, but without much documented evidence; indeed, a Cochrane review reported no increase in venous or arterial thrombotic events with TXA use [9].

Patients with haemophilia are known to have delayed and slow clot formation as well as reduced clot stability, which may be attributed to reduced velocity of thrombin generation, with subsequent delayed Factor XIII (FXIII) and thrombin-activatable fibrinolysis inhibitor (TAFI) activation [10-11]. It has been noted that haemophilic clots are made of thicker fibrin fibres and are thus more susceptible to fibrinolysis [12-13]. An in vivo study by Hvas et al. showed that a combination of TXA and Factor VIII (FVIII) improved clot stability when compared with FVIII alone [14].

The use of antifibrinolytic agents in haemophilia most probably finds its origins in the observation by a haemophilic patient that consumption of roasted peanuts reduced tenderness in acute haemarthrosis [17]. Some authors have described possibility of using peanuts or peanut extracts to increase antifibrinolytic potential, although this is not based on trials [15-16]. Verstraete et al. demonstrated peanut oil to have no statistically proven benefit in 92 haemophiliacs in a double-blinded trial [17].

Further trials in the 1960s concluded that antifibrinolytic agents as prophylaxis did not have a statistically significant effect, although further trials in larger cohorts were indicated [18-20]. Since prophylaxis with specific clotting factors has become the standard of care, this aspect has not been further investigated; however, a combination of clotting factor and TXA is the standard of care for bleeding and for treatment around surgery in many haemophilia centres in Europe [21]. In a retrospective survey, Schulman et al. reported a reduction in total blood loss of up to $50 \%$ using combined treatment with TXA and clotting factor replacement compared to clotting factor replacement alone during orthopaedic surgery [22].

Use of EACA and TXA alongside factor replacement to control local bleeding in dental procedures has been described since the 1960s [23-26]. Sindet- Pedersen demonstrated reduced incidence of post-oral surgery bleeding and reduced factor usage with combined TXA acid use locally and systemically [27]. Waly et al. showed that children with haemophilia who received replacement products prior to dental extraction and local and systemic tranexamic acid developed less post-extraction bleeding than those who did not receive TXA [28], while Nuvvula et al. demonstrated the effectiveness of TXA on its own compared to factor replacement treatment in dental scaling procedures [29]. Mild to moderate haemophiliacs and patients with mild von Willebrand disease (vWD) may only need support with TXA alone for minor procedures (e.g. dental) or minor oral or nose bleeds, or with adjuncts like DDAVP [30]. More haemostatically challenging procedures, such as endoscopy with biopsy, still require the use of replacement clotting factor [31]. Cochrane reviews have acknowledged the effectiveness of TXA in dental procedures and as an adjunct in patients with anti-FVIII neutralising antibodies (inhibitors), whilst also highlighting the lack of well-designed, highquality randomised controlled trials [32-34].

Approximately $20-30 \%$ of haemophilia A patients treated with replacement clotting factor develop neutralising, alloantibodies against FVIII. This is considered the most serious complication in haemophilia therapy due to its impact on factor replacement efficacy, quality of life and resultant morbidity. Patients with persistent inhibitory antibodies require alternative therapy with the bypassing agents (activated prothrombin complex concentrate (APCC) or recombinant FVIIa (rFVIla)) to achieve haemostasis either as regular replacement or episodic to cover acute bleeding episodes or surgery. Antifibrinolytics are used here to optimise efficacy of these agents. Bypassing agents have shown an overall efficacy of 80-90\% [35-36]. Dai et al. demonstrated in a laboratory study that the combination of TXA and APCC improved clot stability in FVIII inhibitor plasma without increase in thrombin generation [37]. A study by Holstorm et al. showed that treatment with APCC and TXA was safe with respect to serious adverse events such as thromboembolic complication and DIC in a limited number of patients $(n=7)$ [38]. Tran et al. also reported the safety of a combination of TXA and bypassing agents [39].

Menorrhagia is common in women with bleeding disorders and is an extremely common presenting symptom in a number of disorders, including, $V W D$, platelet function disorders, Factor VII and Factor XI deficiencies, and in carrier states of haemophilia A and haemophilia B. Kouides et al. demonstrated that TXA is more effective in reducing menorrhagia compared to DDAVP [40]. The safety and effectiveness of TXA in menorrhagia and pregnancy has been demonstrated, and TXA may be used in pregnancy for women with severe bleeding disorders who experience vaginal bleeding [42-43]. Although intrapartum and postpartum bleeding may often need appropriate clotting factor, TXA has been effectively used on its own or as an adjunct [44-46].

\section{Conclusions}

Tranexamic acid remains a versatile yet cheap drug with potential benefits in health services from the lowest to highest income countries. The increasing evidence base supports use of tranexamic acid in acquired and inherited bleeding disorders to reduce bleeding complications, reduce the need for blood product support and improve quality of life. However, there is still a need for welldesigned randomised controlled trials to strengthen the evidence for its use in inherited bleeding disorders. Chaplin et al. provide an important pharmacy review in this issue of The Journal of Haemophilia Practice which contributes further to the literature from which investigators may justify future funding applications.

\section{Disclosures}

The authors have advised no interests that may be perceived 
as posing a conflict or bias.

This is an Open Access article distributed under the terms of the Creative Commons Attribution License (http:// creativecommons.org/licenses/by/2.0), which permits unrestricted use, distribution and reproduction in any medium, provided the original work is properly cited.

\section{References}

1. Reiner, Alexander Paul et al. The fibrinolytic system in man. Critical Reviews in Oncology / Hematology, Volume 2, Issue 1, 33 - 81

2. Raza I, Davenport R, Rourke C, et al. The incidence and magnitude of fibrinolytic activation in trauma patients. J Thromb Haemost 2013; 11(2): 307-14.

3. Okamoto S. Plasmin and antiplasmin. Their pathologic physiology. Keio J Med 1959; 8: 211-7.

4. Okamoto S, Okamoto U. Amino-methyl-cyclohexane-carboxylic acid: AMCHA: a new potent inhibitor of fibrinolysis. Keio J Med 1962; 11: 105-15. 5. Shakur H, Elbourne D, Gülmezoglu M, et al. The WOMAN Trial (World Maternal Antifibrinolytic Trial): tranexamic acid for the treatment of postpartum haemorrhage: an international randomised, double blind placebo controlled trial. Trials 2010, 11: 40.

6. Dewan Y, Komolafe EO, Mejía-Mantilla JH, et al. CRASH-3 - tranexamic acid for the treatment of significant traumatic brain injury: study protocol for an international randomized, double-blind, placebo controlled trial. Trials 2012; 13: 87.

7. Roberts I, Coats T, Edwards P, et al. HALT-IT - tranexamic acid for the treatment of gastrointestinal bleeding: study protocol for a randomised controlled trial. Trials 2014; 15: 450.

8. Roberts I, Shakur H, Afolabi A, et al. The importance of early treatment with tranexamic acid in bleeding trauma patients: an exploratory analysis of the CRASH-2 randomised controlled trial. Lancet 2011; 377: 1096-101.

9. Shakur H, Roberts I, Bautista R, et al. Effects of tranexamic acid on death, vascular occlusive events, and blood transfusion in trauma patients with significant haemorrhage (CRASH-2): a randomised, placebo-controlled trial. Lancet 2010; 376: 23-32.

10. Rea CJ, Foley JH, Ingerslev J, Sørensen B. Factor XIII combined with recombinant factor VIla: a new means of treating severe hemophilia A. J Thromb Haemost 2011; 9: 510-6.

11. Rea CJ, Foley JH, Okaisabor O, Sørensen B. FXIII: mechanisms of action in the treatment of hemophilia A. J Thromb Haemost 2014; 12: 159-68.

12. Brummel-Ziedins KE, Branda RF, Butenas S, Mann KG. Discordant fibrin formation in hemophilia. J Thromb Haemost 2009; 7: 825-32.

13. Foley JH, Nesheim ME, Rivard GE, Brummel-Ziedins KE. Thrombin activatable fibrinolysis inhibitor activation and bleeding in haemophilia A. Haemophilia 2012; 18: e316-22.

14. Hvas A-M, Sørensen HT, Norengaard L, Christiansen K, Ingerslev J, Sørensen B. Tranexamic acid combined with recombinant factor VIII increases clot resistance to accelerated fibrinolysis in severe hemophilia A. J Thromb Haemost 2007; 5: 2408-14.

15. Bisordi MV. Peanut flour in haemophilia. Lancet 1964; $2: 476$.

16. Bruster H. Klin Wochenschr 1961; 39: 1145.

17. Verstraete $M$, Ruys CA. Double-blind experiments on the effect of a peanut extract on the bleeding incidence in 92 haemophiliacs. Br Med J 1967; 4: 453-6.

18. Bennett $A E$, Ingram Gl, Inglish $\mathrm{PJ}$. Antifibrinolytic treatment in haemophilia: a controlled trial of prophylaxis with tranexamic acid. $\mathrm{Br} \mathrm{J}$ Haematol 1973 ;24(1): 83-8.

19. Ingram Gl, Inglish $\mathrm{PJ}$, Bennet AE. Tranexamic acid for prophylaxis in haemophilia. J Clin Pathol $1972 ; 25(7): 629$.

20. Gordon AM, McNicol GP, Dubber AHC, McDonald GA, Douglas AS. Clinical trial of epsilon-aminocaproic acid in severe haemophilia. $\mathrm{Br}$ Med J 1965; 1(5451): 1632-5.

21. Hermans C, Altisent C, Batorova A, et al. Replacement therapy for invasive procedures in patients with haemophilia: literature review, European survey and recommendations. Haemophilia 2009; 15: 639-58. 22. Schulman S, Loogna J, Wallensten R. Minimizing factor requirements for surgery without increased risk. Haemophilia 2004; 10(Suppl. 4): 35-40
23. Tavenner RW. Use of tranexamic acid in control of haemorrhage after extraction of teeth in haemophilia and Christmas disease. Br Med J 1972;2(5809): 314-5.

24. Forbes CD, Barr RD, Reid G, Thomson C, Prentice CR, McNicol GP, Douglas AS. Tranexamic acid in control of haemorrhage after dental extraction in haemophilia and Christmas disease. Br Med J 1972 ;2(5809): 311-3.

25. Walsh PN, Rizza CR, Evans BE, Aledort LM. The therapeutic role of epsilon-aminocaproic acid (EACA) for dental extractions in hemophiliacs. Ann N Y Acad Sci 1975; 240: 267-76.

26. Walsh PN, Rizza CR, Matthews JM, et al. Epsilon-aminocaproic acid therapy for dental extractions in haemophilia and Christmas disease: a double blind controlled trial. Br J Haematol 1971; 20(5): 463-75.

27. Sindet-Pedersen S, Stenbjerg S. Effect of local antifibrinolytic treatment with tranexamic acid in hemophiliacs undergoing oral surgery. J Oral Maxillofac Surg 1986; 44(9): 703-7.

28. Waly NG. Local antifibrinolytic treatment with tranexamic acid in hemophilic children undergoing dental extractions. Egypt Dent J 1995; 41(1): 961-8.

29. Nuvvula S, Gaddam KR, Kamatham R. Efficacy of tranexamic acid mouthwash as an alternative for factor replacement in gingival bleeding during dental scaling in cases of hemophilia: a randomized clinical trial. Contemp Clin Dent 2014; 5(1): 49-53.

30. Laffan MA, Lester W, O'Donnell JS, et al. The diagnosis and management of von Willebrand disease: a United Kingdom Haemophilia Centre Doctors Organization quideline approved by the British Committee for Standards in Haematology. Br J Haematol 2014; 167: 453-65.

31. Davis A, Walsh M, McCarthy P, et al. Tranexamic acid without prophylactic factor replacement for prevention of bleeding in hereditary bleeding disorder patients undergoing endoscopy: a pilot study. Haemophilia 2013; 19: 583-9.

32. Coppola A, Windyga J, Tufano A, Yeung C, Di Minno MN. Treatment for preventing bleeding in people with haemophilia or other congenital bleeding disorders undergoing surgery. Cochrane Database Syst Rev 2015; (2): CD009961

33. Bennett C, Klingenberg SL, Langholz E, Gluud LL. Tranexamic acid for upper gastrointestinal bleeding. Cochrane Database Syst Rev 2014; (11): CD006640.

34. van Galen KPM, Engelen ET, Mauser-Bunschoten EP, van Es RJ, Schutgens RE. Antifibrinolytic therapy for preventing oral bleeding in patients with haemophilia or Von Willebrand disease undergoing minor oral surgery or dental extractions. Cochrane Database Syst Rev 2015; (12): CD011385

35. Negrier C, Goudemand J, Sultan Y, Bertrand M, Rothschild C, Lauroua P. Multicenter retrospective study on the utilization of FEIBA in France in patients with factor VIII and factor IX inhibitors. French FEIBA Study Group. Factor Eight Bypassing Activity. Thromb Haemost 1997; 77: 1113-9.

36. Astermark J, Donfield SM, DiMichele DM et al. A randomized comparison of bypassing agents in hemophilia complicated by an inhibitor: the FEIBA NovoSeven Comparative (FENOC) Study. Blood 2007; 109: 546-51 Epub 2006; doi 10.1182/blood-2006-04-01798.

37. Dai L, Bevan D, Rangarajan S, Sørensen B, Mitchell M. Stabilization of fibrin clots by activated prothrombin complex concentrate and tranexamic acid in FVIII inhibitor plasma. Haemophilia 2011; 17: e944-8.

38. Holmström M, Tran HT, Holme PA. Combined treatment with APCC (FEIBA $囚$ ) and tranexamic acid in patients with haemophilia $A$ with inhibitors and in patients with acquired haemophilia A - a two-centre experience. Haemophilia 2012; 18: 544-9.

39. Tran HT, Sørensen B, Rea CJ, et al. Tranexamic acid as adjunct therapy to bypassing agents in haemophilia A patients with inhibitors. Haemophilia 2014; 20: 369-75.

40. Kouides PA, Byams VR, Philipp CS, et al. Multisite management study of menorrhagia with abnormal laboratory haemostasis: a prospective crossover study of intranasal desmopressin and oral tranexamic acid. Br J Haematol 2009; 145: 212-20.

41. Mohri H. High dose of tranexamic acid for treatment of severe menorrhagia in patients with von Willebrand disease. J Thromb Thrombolysis 2002; 14(3): 255-7.

42. Rybo G. Tranexamic acid therapy: effective treatment in heavy menstrual bleeding: clinical update on safety. Therapeutic Advances 1991; 
4: 1-8.

43. Lindoff C, Rybo G, Astedt B. Treatment with tranexamic acid during pregnancy, and the risk of thrombo-embolic complications. Thromb Haemost 1993; 70(2): 238-40.

44. Kadir RA, Lee CA, Sabin CA, Pollard D, Economides DL. Pregnancy in women with von Willebrand's disease or factor XI deficiency. Br J Obstet Gynaecol 1998; 105(3): 314-21.

45. Ducloy-Bouthors AS, Jude B, Duhamel A, et al. High-dose tranexamic acid reduces blood loss in postpartum haemorrhage. Crit Care 2011; 15(2): R117.

46. Lee CA, Chi C, Pavord SR, et al. The obstetric and gynaecological management of women with inherited bleeding disorders - review with guidelines produced by a taskforce of UK Haemophilia Centre Doctors' Organization. Haemophilia 2006; 12: 301-36.

\section{The Journal of} Haemophilia Practice

An open-access journal for sharing experience in the care of people with bleeding disorders

www.haemjournal.com 